\title{
The Influence of Chengdu Universiade on Tianfu Culture
}

\author{
${ }^{1}$ Enming Zhou \\ ${ }^{1}$ School of physical education, Sichuan University of Arts and Sciences, Dazhou, Sichuan, China \\ Email: ${ }^{a} 2940255673 @ q q . c o m$
}

\begin{abstract}
This paper analyzes the influence of Chengdu Universiade on the spread of Tianfu culture through the methods of literature, field investigation and logical analysis. It includes the following four aspects: sports events, food, ancient Shu civilization and panda. The research found that there are the following problems, lack of corresponding audit and evaluation mechanism, and chengdu Universiade failed to focus on Tianfu culture, and Chengdu Universiade is lack of innovation. In view of the above problems, the following suggestions are put forward, establish the corresponding audit and evaluation mechanism, and build Chengdu Universiade and publiceze Tianfu culture, and with the help of the platforms, we should innovate the cultural path.
\end{abstract}

Keywords: Tianfu culture, Universiade, Sports culture

\section{THE INFLUENCE OF CHENGDU UNIVERSIADE ON THE SPREAD OF TIANFU CULTURE}

\subsection{Sports events to promote urban construction}

In 2018, Chengdu formulated the "three year action plan for Chengdu to build a world famous sports city (2018-2020)", comprehensively promoting the creation of a world famous sports city with first-class stadiums, top brand events, developed sports industry, rich national fitness activities and profound sports culture. In 2020, the proposal of the CPC Chengdu Municipal Committee on formulating the 14th five year plan for Chengdu's national economic and social development and the long-term goal for the year 2035, which was deliberated and approved by the Eighth Plenary Session of the 13th Chengdu Municipal Committee, pointed out that it is necessary to build a world famous city for world events at a high level, adhere to the principle of "planning for the games, operating the city, developing industry and benefiting the people", and successfully run the Universiade, World Table Tennis Championships, Asian Cup, world cup, world cup, world cup, world cup, world cup, world cup, world cup Thomas and Uber cups and major sports events[1].The holding of Chengdu Universiade is insparable to the modern urban construction of Chengdu.
As a city, Chengdu has held several large-scale international events before the Universiade, Chengdu has certain venues and experience. It is reported that there are 49 venues for the 2021 Chengdu Universiade, which are distributed in the main urban area of Chengdu, Xindu District, Qingbaijiang District, Pidu District, Wenjiang District, Shuangliu District, Xinjin Distric, Longquanyi District and Jianyang district. In order to successfully hold the event, Chengdu has accelerated the construction of modern high-tech stadiums, improved the transportation network system, communication network infrastructure, tourism hotels and other supporting facilities. It fully reflects the local economic strength of Chengdu. After the Beijing Olympic Games, the bird's nest has become the city landmark of Beijing, which is also well-known in the world. Chengdu Universiade established three main sports venues, namely: Fenghuangshan Sports Park, Chengbei gymnasium and Chengdu national key table tennis school gymnasium. This time, Fenghuangshan Sports Park adopts international high standards from design to configuration, which can fully meet the international competition requirements of FIBA and NBA. Fenghuangshan sports park is not only the core venue of Chengdu 2021 Universiade, but also an important venue for the 18th Asian Cup in 2023. Chengbei gymnasium was planned and designed according to the requirements and standards of the Universiade competition and training. The top of the gymnasium is surrounded by the rainbow, which 
gradually changes under the sunlight during the day and lights up the night sky at night. It is expected that it will become a brand-new urban sports landmark in the future[2]. In order to make full use of the stadiums built and transformed for the Universiade, Chengdu has also built a sports Chengdu - sports life map (test version). Residents can query the surrounding stadiums in a small program with one click. The address map and contact information are accurate. Some stadiums have also opened the online booking function. In order to do a good job in the radio security work of Chengdu Universiade and improve the professional level of the radio security team of Chengdu Universiade. The Information Technology Department of the Executive Committee of Chengdu Universiade held the Universiade radio security training meeting in Chengdu in February 2021. The training included different requirements of pre competition and during competition, and elaborated the main challenges and solutions in venue operation and management. The Universiade accelerated the construction of Chengdu Radio[3].

\subsection{Gourmet city, relying on Creative City Network}

First, Chengdu is an inclusive city, forming a variety of food culture. Chengdu has experienced six large-scale national migration and large-scale migration in history, and the integration of various folk culture has made Chengdu food materials and production methods diverse, and the food culture has been enriched and prosperous in exchange and innovation. Besides the rich local Sichuan cuisine, foreign and foreign dishes are also colourful. Secondly, Chengdu cuisine culture originated from Oriental philosophy. Chengdu has numerous delicious foods. The most important feature of Chengdu cuisine is its rich taste. It can blend 23 kinds of compound flavours with five basic flavours, namely, sweet, sour, bitter, spicy and salty. This food idea and food culture originated from the ancient philosophy of our country. The ancient philosophers in the early autumn and Warring States period put forward that the universe and life are unified, and five basic elements, gold, wood, water, fire and earth, constitute all things in the universe. Chengdu cuisine is the inheritance of this concept, based on the five flavours, absorbing the characteristics and essence of many dishes throughout the country, and finally evolved into Chengdu's unique catering culture. It has become one of the most delicacy schools in the cuisine of China, even in the international cuisine. Third, Chengdu's rich products provide raw material for food. Chengdu is located in the middle and upper reaches of the Yangtze River, with abundant water, with 12 main streams and dozens of tributaries; The water quality is excellent and the pollution is very small. It produces a lot of fresh water fish, shrimp, shellfish and aquatic plants every year. As a rich basin topography, Chengdu Plain accounts for more than $50 \%$ and the rest is low hills. There are many minerals and the soil is beautiful. It can produce a lot of foods, oils, fruits, vegetables, bacterias, shoots, tea and so on. Chengdu has good vegetation and has biological resources of various landforms. The coverage rate of urban greening is high. There are a great variety of animals and plants. Pigs, sheep, chickens, ducks, rabbits and other livestock also produce a large amount. Chengdu has the unique geographical resources for Chengdu people, Shuangliu county produces chili, known as "the best chili in the world"; Bean petals produced in Pixian County are known as "the soul of Sichuan cuisine". The so-called "taste in Sichuan, soul is Pixian County", which means Pixian bean petals. Since the birth of Pixian bean petals in the late Ming and early Qing Dynasty, Sichuan cuisine has been developed and honored internationally.

\subsection{Ancient Shu civilization promotes tourism economy}

Ancient Shu civilization refers to the ancient civilization from ancient times to the early spring and autumn period, which originated from Sichuan (including Sichuan Province and Chongqing) and is different from the Central Plains Civilization, but has countless ties with the Central Plains Civilization. At present, the main remains are Chengdu Jinsha site and Sanxingdui site. Together with the Chinese civilization and Liangzhu civilization, they are called the three ancient civilizations of China. Sanxingdui, Chaotian zizipu, Danba middle road in Guanghan, Sichuan, Kaiming Royal boat coffin in Jinsha and commercial street in Chengdu, Baodun in Xinjin and wangcong temple in Pidu are all sites of ancient Shu civilization. As a tourist city, Chengdu has not only ancient Shu civilization sites, but also Wuhou Temple, Jinli and Dufu thatched cottage. There are also mature Dujiangyan Qingcheng Mountain tourist routes, Leshan Emeishan tourist routes and so on. Chengdu is known as a mature tourism city by the industry. It is not only rich in tourism resources, but also suitable for vacation and leisure" "Bashi" is the label of Chengdu, occupying all kinds of tourism lists for a long time. In May 2021, according to the statistics released by china.com, Chengdu will achieve a total tourism revenue of 17.02 billion during May 1, 2021, ranking second in China; It received 18.505 million tourists, ranking first in China[4].

\subsection{Panda home, shaping city symbol}

On August 19, 2020, Chengdu held the first anniversary of the countdown to the Chengdu Universiade, and the naming ceremony of Chengdu Universiade mascot "Rongbao" was officially launched. After global voting, the giant panda "sesame" from Chengdu Giant Panda Breeding Research Base has become the real image of the mascot "Rongbao" of Chengdu Universiade, and launched a global live broadcast for fans at home and abroad. As the real mascot 
and unique new business card of Chengdu Universiade, "Rongbao" as a cartoon image of various sports has also entered the streets of Chengdu. On February 9, 2021, Chengdu held the "colourful Universiade . panda's departure" - Chengdu Universiade "painted Rongbao" global creative collection activity in Kuanzhai alley. Six new year themed Rongbao art paintings made a spectacular appearance. Taking the sculpture prototypes of three postures of the mascot of Chengdu Universiade, giant panda Rongbao, as the creative carrier, and taking "the integration and interaction of representative cultural elements of participating countries and Chinese cultural elements" as the creative proposition, the activity received the participation of artists, designers and art groups from all over the world.

\section{THE MAIN PROBLEMS IN THE SPREAD OF TIANFU CULTURE IN CHENGDU UNIVERSIADE}

\section{1. lack of corresponding audit and evaluation mechanism}

The development of Chengdu Universiade is obviously a good opportunity to promote consumption for Chengdu. Among them, some businesses also publicize the Universiade without the right to name it. It is a good thing for these businesses to publicize the Chengdu Universiade for free, but some businesses focus on the Universiade and sell some sports products with poor quality. In this case, when consumers get sports products with quality problems, due to asymmetric information, they will attribute the quality problems to the failure of the Universiade audit.

\subsection{Chengdu Universiade failed to focus on Tianfu culture}

Chengdu has held several large-scale international events before the Universiade, so the Universiade has not attracted enough attention. In the context of COVID-19, the focus of attention is on the epidemic. Whether the Universiade is bound to develop is also a problem. The success of Beijing Olympic Games is that the 2008 Olympic Games let the world remember Beijing and publicize Chinese culture and Beijing culture. Chengdu should take the Chengdu Universiade as an opportunity to publicize Chinese culture and Tianfu culture.

\section{3 lack of innovation in Chengdu Universiade}

Chengdu Universiade has not been held yet, but from the early publicity, there is no innovation. Beijing Olympic Games and Winter Olympic Games are held in the early stage of a large number of publicity, theme song and mascot has become the symbol of the event, the bird's Nest stadium after the event, is one of the landmark buildings of Beijing. At present, the three main stadiums and mascots of Chengdu Universiade are not publicized.

\section{SUGGESTIONS}

\section{1 establish the corresponding audit and evaluation mechanism}

Chengdu Universiade itself has a competition committee. The Games Committee should establish the corresponding audit and evaluation mechanism and strictly control the naming right. The principles of the construction of the audit and evaluation mechanism should follow the principles of science, system, feasibility and comprehensiveness. Then, the evaluation index is constructed by referring to the theoretical basis, the opinions of experts and scholars and the experience of sports events evaluation. The evaluation indexes can be divided into primary index and secondary index. After the evaluation index is initially completed, the indicators are adjusted by interviewing with experts one-on-one. After adjustment, the expert scoring and weight are carried out to determine the weight number of indicators [5].

\section{2 build Chengdu Universiade and publicize Tianfu culture}

Chengdu has a very rich culture of Tianfu. It is necessary to take advantage of the opportunity of Chengdu Universiade to drive economy with culture. As the source of one quarter of GDP in Sichuan Province, Chengdu should attach importance to the organizing and publicity of the games, deeply tap into Tianfu culture, using the platform of the Universiade, focusing on introducing sports sponsorship from well-known enterprises at home and abroad, strengthening economic and cultural exchanges and cooperation, and build Chengdu Tianfu City brand. For Chengdu, hosting the Universiade is an excellent opportunity to improve the level of internationalization, promote the rapid improvement of urban function and quality, and fully display the style of Chengdu. It can improve the style of urban construction and enhance the image of the city. Through the holding of sports events, the attraction of investment will be further enhanced[6].

\section{3 reasonabl use of platform and innovative cultural path}

From 2018 to 2020, Chengdu held more than 60 international sports events. With the reasonable help of these events, it can focus on building a famous international sports city. Among the three main stadiums of the Universiade, the North City Gymnasium with distinctive characteristics is selected as the key publicity object, the symbol memory is strengthened, and the 
theme publicity activities on the mascot "Rong Bao" are carried out.

\section{CONCLUSION}

In addition to the Universiade, Chengdu will also host many large-scale international events in the next few years. Then, Chengdu should take advantage of the opportunity to undertake competitions, take competitions as the media, and seek production through competitions, so as to provide opportunities for creating a fitness scene for the masses, and provide opportunities for revitalizing the western sports industry, so as to strengthen the work of high-quality construction of the world famous city of sports events[7]. The influence of Chengdu Universiade on the development of Tianfu culture is an objective factor, which has played and is playing an important role. However, in order to hold the Chengdu Universiade better, the influence of Tianfu culture is more farreaching. All flowers bloom together. The city culture is more advanced and more modern. At the same time, we should pay attention to improving the public welfare cultural undertakings and supporting the business cultural industries. Public cultural undertakings are the public cultural space of the city, which directly serve the public. Only by building a good public cultural space and giving play to the guiding role of public cultural undertakings in values and aesthetic taste, can we resist the assimilation and misleading of foreign cultures. Only by fostering business culture can we have advantages in entertainment, appreciation and knowledge, and build a perfect cultural industry [8]. Chengdu's future of hosting international sports events is the witness of the city's rapid internationalization. At the time of the construction of Chengdu Chongqing double City Economic Zone, Chengdu, standing at a new starting point, is making great strides towards the goal of being a famous city for international competitions [9].

\section{REFERENCES}

[1] Wang Qingwei. Run the Universiade with high quality and solve the problem of using the venues after the competition rationally [J]. Xianfeng, 2021 (01): $26-28$

[2] Yang pan. The influence of large scale sports events on urban development [J]. Journal of Hubei correspondence university, 2015,28 (21): 70-71

[3] Lu Yingbing. Radio security training organized by Information Technology Department of Chengdu Universiade Executive Committee [J]. China Radio, 2021 (03): 7

[4] Wu CE, Yiding. Tourism revenue of May 1 city: Shanghai is far ahead, Chengdu has the most tourists [EB]. China com. http://travel.china.com.cn/txt/2021-05/10/content_ 77478365.html.2021-5-10

[5] Tao Tao. Construction of evaluation index system for government funded mass sports events [D] Shenzhen University, 2019

[6] Luo Laijun. The Universiade promotes Chengdu into the ranks of "extreme nuclear city" [J]. Pioneer, 2020 (08): 21-24

[7] Bao Mingxiao, Zhao Jianyuan. Universiade empowers high quality innovation and development in Chengdu [J]. Xianfeng, 2020 (08): 17-20

[8] Yuan maoshuan. Analysis of the influence of the 2008 Olympic Games on the cultural development of the capital [J]. Urban issues, 2004 (06): 52-57

[9] Wang Haoming. From small fishing village to the capital of international sports events $[\mathrm{J}]$. China industry economics, 2020 (18): 71-73 